\title{
JUURNAL.RU
}

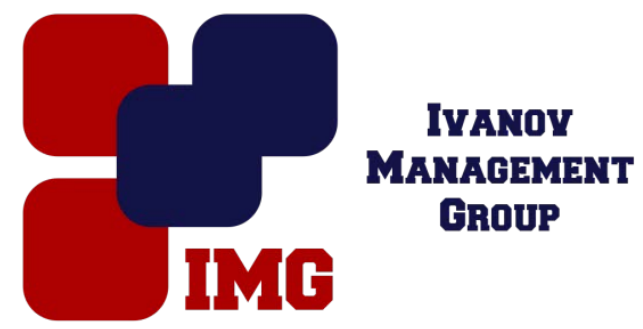

Винокуров Г.М., Мамаева А.И. Иркутский государственный аграрный университет имени А.А. Ежевского Иркутск, Россия

doi: 10.18411/lj-25-12-2016-3-08

idsp 000001:lj-25-12-2016-3-08

\section{Рентабельность сельскохозяйственного производства в коллективных хозяйствах Иркутской области}

\section{Аннотация}

В статье рассматривается финансовое состояние коллективных хозяйств области, уровень выручки, прибыли, рентабельности, цены и себестоимость отдельных видов продукции, запас финансовой прочности, колебание рентабельности. Особое внимание уделено на уровень урожайности, продуктивности: фактической, производственной и коммерческой. Показана производственная и коммерческая себестоимость основных видов производимой продукции, связь между ценой и коммерческой себестоимостью. Рентабельность произведенной продукции и основные направления для увеличения производства продукции.

Ключевые слова: выручка, себестоимость, цена, маржа производственная и коммерческая, рентабельность.

Успешная деятельность предприятия зависит в первую очередь от количества получаемой выручки от реализации продукции и от продажи услуг, которые в сумме представляют валовой доход предприятия. Предприятие за счет этого платит налоги, начисляет заработную плату и получает чистую прибыль. Прибыль основной источник социальных выплат и ведения расширенного воспроизводства [2].

При распределении прибыли необходимо сочетание интересов собственника, интересов коллектива предприятия и конкретного работника. Прибыль - основной источник расширения производства и других потребностей предприятия. При распределении прибыли учитывают все потребности предприятия. В сельскохозяйственном производстве у большинства участников потребностей намного больше, чем имеется в наличии источников. При недостатке средств используют кредиты, но их необходимо возвращать и оплатить за них определенную сумму процентов.

Показателем эффективности работы предприятия является рентабельность. В ходе анализа увеличения прибыли рассчитывают рентабельность по разным видам продукции для определения наиболее выгодных видов, либо после расчета 
рентабельности рассматривают другие пути роста прибыли.

В Иркутской области в период с 2011 по 2014 год экономическая ситуация по основным видам сельскохозяйственной деятельности следующая: около $81 \%$ товарной продукции производится в животноводстве (таблица 1), 12\% приходится на растениеводство, остальное занимает прочая продукция сельского хозяйства. Наиболее прибыльными отраслями животноводства являются птицеводство и свиноводство, к тому же рентабельность свиноводства среди всех отраслей сельского хозяйства области самая высокая - 29,4\%. Разведение крупного рогатого скота в Иркутской области на протяжении значительного периода является убыточным.

Таблица 1

Структура, прибыль и рентабельность товарной продукции по сельхозорганизациям Иркутской области

\begin{tabular}{|c|c|c|c|c|c|c|}
\hline \multirow{2}{*}{ Показатели } & \multicolumn{3}{|c|}{$2006-2010$ годы } & \multicolumn{3}{c|}{ 2011-2014 годы } \\
\cline { 2 - 7 } & $\begin{array}{c}\text { структура, } \\
\%\end{array}$ & $\begin{array}{c}\text { прибыль, } \\
\text { млн. руб. }\end{array}$ & $\begin{array}{c}\text { рентабельн } \\
\text { ость, } \%\end{array}$ & $\begin{array}{c}\text { структура, } \\
\%\end{array}$ & $\begin{array}{c}\text { прибыль, } \\
\text { млн. руб. }\end{array}$ & $\begin{array}{c}\text { рентабельн } \\
\text { ость, \% }\end{array}$ \\
\hline Растениеводство & 15,5 & 183 & 12,7 & 12 & 102 & 5,6 \\
\hline зерновые & 7 & 114 & 16,5 & 6,5 & 126 & 13,8 \\
\hline картофель & 2,1 & 46 & 27,7 & 1,4 & 13 & 6,2 \\
\hline овощи & 3,5 & -4 & -1 & 2,3 & -64 & $-15,2$ \\
\hline Животноводство & 79,9 & 1070 & 14,7 & 81,2 & 1753 & 15,6 \\
\hline крупный рогатый скот & 5,5 & -196 & $-25,3$ & 4,9 & -194 & $-19,9$ \\
\hline молоко & 17,6 & 256 & 15,1 & 17,5 & 352 & 14,4 \\
\hline скотоводство & 23,1 & 60 & 2,5 & 22,4 & 158 & 4,6 \\
\hline свиноводство & 17,8 & 414 & 25,4 & 20,6 & 750 & 29,4 \\
\hline яйцо & 18,6 & 380 & 24,2 & 15,2 & 270 & 12,5 \\
\hline мясо птицы & 12,3 & 213 & 11,4 & 22,1 & 538 & 17,9 \\
\hline птицеводство & 37,9 & 539 & 15,5 & 37,3 & 808 & 15,6 \\
\hline Прочее & 4,6 & -20 & $-3,7$ & 6,8 & -176 & $-19,8$ \\
\hline Всего реализации & $100 / 88,2$ & 1233 & 13,3 & $100 / 88,1$ & 1679 & 11,6 \\
\hline Прочие доходы и & 11,8 & 598 & 75 & 11,3 & 832 & 64,8 \\
расходы (переработка) & 100 & 1831 & 18,2 & 100 & 2511 & 16,1 \\
\hline Итого & - & 1831 & 16,8 & - & 2511 & 16,4 \\
\hline Чистая прибыль & - & 1206 & - & - & 1531 & \\
\hline Дотации & - & 11,5 & - & - & 9,6 & \\
\hline Дотации на рубль & - & & & & \\
\hline выручки, коп. & - & & & & & \\
\hline
\end{tabular}

* Разработано автором на основе данных Министерства сельского хозяйства Иркутской области

Что касается отраслей растениеводства, то рост наблюдается только по производству зерновых, по картофелю и овощам происходит спад, кроме того в овощеводстве идет нарастание убыточности. Это связано с тем, что снижается их урожайность, становится мало тех предприятий, которые были задействованы в этой отрасли. Те же причины влияют на производство картофеля. Основными производителями картофеля в области являются личные подсобные хозяйства, их широкая география, как правило, обеспечивают устойчивую урожайность и заполняют рынок сбыта, к сожалению рынок для них не организован, что дает возможность отдельным продавцам продавать его по относительно повышенным ценам. Необходимо отметить, что удельный вес производства продукции растениеводства имеет тенденцию к снижению. Вызвано это, как правило, низкой рентабельностью и недостаточным спросом на продукцию и конкурентами, здесь выступают китайские производители, занятые в Китае и России.

С точки зрения политики импортозамещения перспективными отраслями 
являются свиноводство и мясное птицеводство, так как рентабельность данных отраслей возрастает. Увеличение производства продукции этих отраслей связано с привлечением инвестиций, а для инвесторов рост рентабельности производства один из мотивов для вложения средств. Ситуация с увеличением производства продукции в свиноводстве складывается таким образом, что самый оптимальный вариант роста производства связан с модернизацией существующих предприятий для повышения производства свинины, а также привлечения большего количества крестьянских фермерских хозяйств в свиноводство.

Таблица 2

Маржа, запас финансовой прочности по сельскохозяйственным организациям Иркутской области за 2012-2014 годы

\begin{tabular}{|c|c|c|c|c|c|c|c|c|c|c|c|c|}
\hline \multirow{2}{*}{ Показатели } & \multicolumn{12}{|c|}{ Годы } \\
\hline & \multicolumn{4}{|c|}{2012} & \multicolumn{4}{|c|}{2013} & \multicolumn{4}{|c|}{2014} \\
\hline Зерно & 2956 & 29,8 & 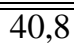 & $\begin{array}{l}13,8 \\
\end{array}$ & 1007 & "35 & "43,8 & 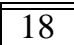 & $\begin{array}{l}1267 \\
\end{array}$ & 29,9 & "40,9 & (13,9 \\
\hline Картофель & 202 & 8,2 & - & $-8,5$ & 181 & 17 & - & - & 218 & 16 & - & $-2,2$ \\
\hline $\begin{array}{c}\text { Овощи } \\
\text { открытого } \\
\text { грунта }\end{array}$ & 68 & - & - & $-18,8$ & 82 & - & - & - & 83 & 8,4 & - & $-6,7$ \\
\hline $\begin{array}{c}\text { Овощи } \\
\text { закрытого } \\
\text { грунта } \\
\end{array}$ & 243 & - & - & -17 & 352 & 2,6 & - & - & 261 & 9,6 & - & $-7,4$ \\
\hline $\begin{array}{c}\text { Растение } \\
\text { водство }\end{array}$ & 1702 & 14,1 & - & $-3,4$ & 1908 & 24,4 & 19,7 & 5 & 2140 & 24,8 & 28,4 & 7.5 \\
\hline Молоко & 1145 & 29,4 & 40,2 & 13,5 & 1318 & 29,2 & 32,7 & 10,6 & 1379 & 29,4 & 40 & 13,9 \\
\hline Привес КРС & 426 & 6,2 & - & $-10,5$ & 362 & - & - & - & 35,3 & - & - & -20 \\
\hline Свинина & 64 & 18,7 & - & -4 & 7,8 & 16,7 & - & - & 42 & - & - & $-22,2$ \\
\hline Птица & 61 & 21 & 15,6 & 3,4 & 75 & 21,3 & - & 25 & 83 & 12 & - & $-3,5$ \\
\hline Яйцо & 2315 & 30,2 & 41,6 & 14,3 & 3549 & 30,8 & 36,2 & 12,6 & 2693 & 28 & 36,4 & 11,4 \\
\hline Мед & 4,2 & 22,3 & 17,3 & 4 & 5,6 & 61,5 & 62,2 & 67,7 & 5,8 & 41,4 & 164 & 31,8 \\
\hline \multicolumn{13}{|l|}{$\begin{array}{c}\text { Переработка } \\
:\end{array}$} \\
\hline Молоко & 1402 & 33,5 & 36,3 & 13,9 & 1584 & 34,2 & 42,8 & 17,2 & 1901 & 29,5 & 39,7 & 13,2 \\
\hline Привес КРС & 360 & - & - & $-25,7$ & 330 & - & 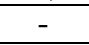 & - & 284 & 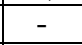 & - & $-25,3$ \\
\hline Свинина & 3107 & 42,1 & 58 & 24,4 & 3353 & 43,6 & 54,8 & 31,5 & 3789 & 40,4 & 56 & 29,2 \\
\hline Птица & 3365 & 40,2 & 56,2 & 25,2 & 3395 & 35,8 & 45,2 & 19,2 & 4460 & 30,6 & 42 & 14,7 \\
\hline $\begin{array}{c}\text { Итогоживот } \\
\text { новодства }\end{array}$ & 12422 & 33,5 & 47,3 & 18,8 & 13210 & 33,2 & 40,8 & 15,6 & 15258 & 30 & 40,9 & 14,1 \\
\hline $\begin{array}{c}\text { Прочая } \\
\text { продукция }\end{array}$ & 1290 & 10,5 & - & $-6,8$ & 1155 & - & - & - & 1215 & 15 & - & $-2,6$ \\
\hline Всего & 15415 & 29,4 & 40 & 13,3 & 16283 & 28,6 & 31.3 & \begin{tabular}{|l|}
9,8 \\
\end{tabular} & 18613 & 24,5 & 27,6 & 12 \\
\hline
\end{tabular}

При делении затрат на постоянные и переменные важное место занимает маржа, точка безубыточности и запас финансовой прочности [1]. Для любого производства затраты можно разделить на постоянные и переменные, при этом в разных производствах удельный вес постоянных расходов не одинаковый. К постоянным расходам относят расходы, которые в определенном объеме не изменяются с изменением объема производства. Точка безубыточности показывает минимальный размер продажи для получения нужного результата от реализации продукции. Запас финансовой прочности - разница между суммой продажи и фактической реализацией, данный показатель можно рассчитать в натуральном выражении, денежном и в процентах. Любое производственное предприятия стремится получить больше маржи, т.е. разницы междувыручкой и переменными затратами. В целом по сельхозорганизациям в области за три анализируемых годамаржа составила 29,4\% в 2012 году,в 2013году - 28,6 \% и 24,5 \% в 2014году. В растениеводстве финансовые результаты более низкие, чем в 
животноводстве, в целом предпочтение можно отдать производству зерна, молока, яйца,меда и продажи переработанной продукции мяса свиней и птицы. В целом финансовое положение в мелких предприятиях не стабильное, более устойчивыми являются специализированные агрокомплексы. Остальные хозяйства, как правило, заняты производством зерна, крупного рогатого скота в виде молока и привеса.В свиноводстве и птицеводствеприбыльно работают промышленные предприятия, но для дальнейшего развития всех отраслей нужны опорные точки для увеличения производства продукции в области[3,4].

Важным фактором получения прибыли является уровень урожайности и продуктивности, так этот уровень определяет производственную себестоимость продукции.

Таблииа 3

Урожайность, продуктивность в сельскохозяйственных организачиях Иркутской области

\begin{tabular}{|c|c|c|c|c|c|c|c|c|c|}
\hline \multirow{4}{*}{ Продукция } & \multicolumn{9}{|c|}{ Годы } \\
\hline & \multirow{2}{*}{\multicolumn{3}{|c|}{$\begin{array}{c}2012 \\
\text { Урожайность, ц/га } \\
\text { (продуктивность, кг) }\end{array}$}} & \multirow{2}{*}{\multicolumn{3}{|c|}{$\begin{array}{c}2013 \\
\begin{array}{c}\text { Урожайность, ц/га } \\
\text { (продуктивность, кг) }\end{array}\end{array}$}} & \multirow{2}{*}{\multicolumn{3}{|c|}{$\begin{array}{c}2014 \\
\text { Урожайность, ц/га } \\
\text { (продуктивность, кг) }\end{array}$}} \\
\hline & & & & & & & & & \\
\hline & \multirow{2}{*}{$\begin{array}{l}8 \\
16,9\end{array}$} & \multicolumn{2}{|c|}{$\begin{array}{c}\text { Безубыточность, } \\
\text { руб }\end{array}$} & \multirow{2}{*}{$=8$} & \multicolumn{2}{|c|}{$\begin{array}{c}\text { Безубыточность, } \\
\text { руб } \\
\end{array}$} & \multirow{2}{*}{$=\begin{array}{l}E 8 \\
21,3\end{array}$} & \multicolumn{2}{|c|}{$\begin{array}{c}\text { Безубыточность } \\
\text { руб }\end{array}$} \\
\hline Зерно & & 14,0 & 14,9 & & $\overline{15,1}$ & 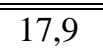 & & $\overline{17,0}$ & $\begin{array}{ll}18,7 \\
\end{array}$ \\
\hline Картофель & 216 & 141 & 236 & 139 & 93 & 141 & 175 & 117 & 179 \\
\hline $\begin{array}{c}\text { Овощи открытого } \\
\text { грунта }\end{array}$ & 260 & 183 & 321 & 165 & 141 & 207 & 248 & 124 & 268 \\
\hline $\begin{array}{c}\text { Овощи закрытого } \\
\text { грунта }\end{array}$ & 0,16 & 0,18 & 0,19 & 0,22 & 0,24 & 0,25 & 0,21 & 0,25 & 0,26 \\
\hline Ягоды & 1,5 & 4,8 & 3,6 & 1,5 & 0,72 & 1,4 & 1,6 & 1,25 & 1,08 \\
\hline Живой вес КРС & 1,74 & 2,5 & 2,0 & 2,0 & 3,67 & 2,53 & 2,19 & 3,03 & 2,74 \\
\hline Свиней & 1,92 & 1,7 & 2,0 & 2,05 & 1,42 & 1,92 & 2,05 & 1,79 & 2,65 \\
\hline Птицы & 0,12 & 0,06 & 0,12 & 0,13 & 0,1 & 0,11 & 0,14 & 0,08 & 14,3 \\
\hline Молоко & 42,0 & 31,0 & 37,0 & 46,1 & 27,3 & 40,4 & 49,4 & 36,9 & 43,4 \\
\hline Мед & 0,29 & 0,29 & 0,28 & 0,39 & 0,24 & 0,23 & 0,44 & 0,28 & 0,33 \\
\hline \multicolumn{10}{|l|}{ Переработано: } \\
\hline Молоко & 42,0 & - & 37,0 & 46,1 & - & 39,4 & 49,4 & - & 43,6 \\
\hline KPC & 1,77 & - & 2,38 & 2,0 & - & 2,8 & 2,2 & - & 2,9 \\
\hline Свиней & 1,9 & - & 1,5 & 2,1 & - & 1,2 & 2,1 & - & 1,6 \\
\hline Птицы & 0,13 & - & 0,1 & 0,13 & - & 0,1 & 0,14 & - & 0,12 \\
\hline
\end{tabular}

В основном за исследуемый период наблюдается увеличение урожайности и продуктивности по представленным видам продукции. Сокращение урожайности наблюдается только по картофелю и овощам открытого грунта. Данная ситуация складывается по причине того, что выращиванием картофеля кроме сельхозпредприятий занимается частный сектор, а также большие объемы импорта. Зачастую продукция местных товаропроизводителей несколько выше, чем продукция, завезенная из Китая. Для населения в кризисной ситуации на первый план выходит цена продукта, а его качество встает на второй план. Снижение спроса на продукцию толкает местные сельхозпредприятия снижать производство картофеля. Такая же ситуация обстоит и по овощам закрытого грунта. Рост безубыточности как производственной, так и коммерческой, данных видов продукции прослеживается за весь рассматриваемый период. 
Таблиия 4 Себестоимость и иена по сельскохозяйственным организациям Иркутской области в рублях

\begin{tabular}{|c|c|c|c|c|c|c|c|c|c|}
\hline \multirow{3}{*}{ Вид продукции } & \multicolumn{9}{|c|}{ Годы } \\
\hline & \multicolumn{3}{|c|}{2012} & \multicolumn{3}{|c|}{2013} & \multicolumn{3}{|c|}{2014} \\
\hline & \multicolumn{2}{|c|}{ Себестоимость } & \multirow{2}{*}{ 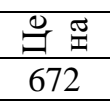 } & \multicolumn{2}{|c|}{ Себестоимость } & \multirow{2}{*}{ 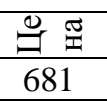 } & \multicolumn{2}{|c|}{ Себестоимость } & \multirow{2}{*}{ 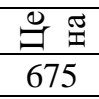 } \\
\hline Зерно & 555 & 591 & & 566 & 577 & & 538 & 593 & \\
\hline Картофель & 535 & 894 & 818 & 768 & 1168 & 1147 & 764 & 1167 & 1166 \\
\hline $\begin{array}{c}\text { Овощи } \\
\text { открытого } \\
\text { грунта } \\
\end{array}$ & 473 & 829 & 673 & 799 & 1177 & 939 & 657 & 1426 & 1318 \\
\hline $\begin{array}{c}\text { Овощи } \\
\text { закрытого } \\
\text { грунта } \\
\end{array}$ & 6486 & 6974 & 5790 & 7467 & 7966 & 6745 & 8865 & 8405 & 7781 \\
\hline Ягоды & 18832 & 11731 & 5739 & 7737 & 6053 & 6579 & 8406 & 7290 & 10774 \\
\hline Живой вес КРС & 12785 & 10225 & 9155 & 14560 & 10252 & 7971 & 14625 & 12144 & 9708 \\
\hline Свиней & 9448 & 11070 & 10632 & 10548 & 12817 & 15173 & 10302 & 15253 & 11785 \\
\hline Птицы & 4457 & 9546 & 9866 & 5371 & 5789 & 6912 & 5740 & 11231 & 10827 \\
\hline Молоко & 1578 & 1890 & 2145 & 1747 & 2582 & 2945 & 1764 & 2074 & 2360 \\
\hline Яйцо & 2014 & 2597 & 2969 & 2341 & 2824 & 3182 & 2393 & 2963 & 3300 \\
\hline Мед & 31562 & 30022 & 31228 & 20780 & 20038 & 32892 & 15675 & 21200 & 27971 \\
\hline \multicolumn{10}{|l|}{ Переработка: } \\
\hline Молоко & - & 2689 & 3055 & - & 3018 & 3533 & - & 3172 & 3594 \\
\hline КРC & - & 11778 & 8744 & - & 12413 & 8847 & - & 12977 & 9711 \\
\hline Свиней & - & 12205 & 16139 & - & 12743 & 16752 & - & 13854 & 17898 \\
\hline Птицы & - & 5351 & 6913 & - & 5338 & 6848 & - & 7096 & 8142 \\
\hline
\end{tabular}

За три года, представленных в таблице 4, себестоимость и цена продукции росли за счет инфляции. Цена зерна почти не изменилась, также медленно росла цена на говядину и мед, значительный рост цен наблюдается по картофелю, овощам открытого и закрытого грунта, ягодам.Продажа молока, яйца, меда, переработанной птицы и свинины приносят прибыль, выше сумма маржи, выше запас финансовой прочности и рентабельности. При этом изменение по годам не сильно заметно, но в последние годы ясно повышает интерес производство мяса птицы, свинины и снижается эффективность производства яйца. Особое место занимает производство говядины, которая убыточна при продаже в живом весе и переработанном, надежды на развитие данной отрасли в ближайшее время сомнительны. Производство продукции пчеловодства незначительно, но имеет смысл обратить внимание на эту отрасль, тем более что возможности для увеличения продукции есть, и рынок местной продукцией не заполнен.

Основные направления увеличения производства продукции в регионе следующие: при производстве зерна необходимо по возможности разрабатывать как можно больше земель для обеспечения возросших возможностей развития животноводства с учётом роста урожайности не менее 20 центнеров с гектара.

В производстве картофеля необходимо ограничить привоз картофеля из Китая, Израиля, за счёт повышения таможенной оплаты, дальнейшее проектирование переработки картофеля в области; в производстве свинины строительство - свинокомплекса и поддержка мелких производителей доступными способами; в скотоводстве - поддержка отрасли за счёт дотации всех участников производственного процесса, укрепление материально-технической базы отрасли и повышение оплаты труда.

Центральное место занимает увеличение поддержки отраслей сельского хозяйства за счёт дотации на уровне до 20 процентов от суммы выручки с 
распределением её с учётом выравнивания рентабельности отраслей.

При нормальных условиях уровень рентабельности активов должен стремиться примерно к одинаковой величине, поэтому уровень наценки в разных участках движения товаров (производство, переработка, реализация) должен быть разным. Наценка на продукцию сельскохозяйственных производителей должна составлять 52\% от общей суммы наценки на конечный продукт, переработчики должны получать около $11 \%$, а магазины, которые непосредственно реализуют продукцию населению - только $2 \%$. В таком случае производители будут получать наибольшую выгоду и развивать производство, наращивая объемы, а спекулятивные доходы снизятся.

\section{Литература}

1. Винокуров Г.М. Анализ и диагностика финансово-хозяйственной деятельности предприятия // Г.М. Винокуров: Иркутск. - ИрГСХА. - 2008. $-360 \mathrm{c}$.

2. Винокуров Г.М. Современное состояние и перспективы развития сельскохозяйственного производства в Иркутской области // Г.М. Винокуров: Иркутск. - ИрГСХА. - 2010. - 164 с.

3. Винокуров Г.М. Состояние основных фондов и источники их обновления в сельском хозяйстве // Винокуров Г.М., Винокуров С.И., Леус Т.В.: Иркутск. - ИрГСХА. - 2015. - 114 с.

4. Губанов С. Неоиндустриализация России и нищета её собственной критики / Экономист. - 2014, №4. - С. 3-32.

5. Тяпкина М.Ф. Инвестиционная привлекательность предприятия: теоретический аспект // М.Ф. Тяпкина, Е.А. Ильина: Иркутск. -ИрГСХА. 2013. - 80c. 